\title{
Balanced massive transfusion ratios in multiple injury patients with traumatic brain injury
}

Sigune Peiniger ${ }^{1,2}$, Ulrike Nienaber ${ }^{2}$, Rolf Lefering ${ }^{2}$, Maximilian Braun ${ }^{1,2}$, Arasch Wafaisade $^{1,2}$, Sebastian Wutzler ${ }^{1}$, Matthew Borgmann ${ }^{3}$, Philip C Spinella ${ }^{4}$ and Marc Maegele ${ }^{1,2^{*}}$, for the Trauma Registry of the Deutsche Gesellschaft für Unfallchirurgie (TR-DGU)

\begin{abstract}
Introduction: Retrospective studies have demonstrated a potential survival benefit from transfusion strategies using an early and more balanced ratio between fresh frozen plasma (FFP) concentration and packed red blood cell (pRBC) transfusions in patients with acute traumatic coagulopathy requiring massive transfusions. These results have mostly been derived from non-head-injured patients. The aim of the present study was to analyze whether a regime using a high FFP:pRBC transfusion ratio (FFP:pRBC ratio $>1: 2$ ) would be associated with a similar survival benefit in severely injured patients with traumatic brain injury (TBI) (Abbreviated Injury Scale (AIS) score, head $\geq 3$ ) as demonstrated for patients without TBI requiring massive transfusion ( $\geq 10 \mathrm{U}$ of pRBCs).
\end{abstract}

Methods: A retrospective analysis of severely injured patients from the Trauma Registry of the Deutsche Gesellschaft für Unfallchirurgie (TR-DGU) was conducted. Inclusion criteria were primary admission, age $\geq 16$ years, severe injury (Injury Severity Score $(I S S) \geq 16$ ) and massive transfusion ( $\geq 10 \cup$ of pRBCs) from emergency room to intensive care unit (ICU). Patients were subdivided into patients with TBI (AIS score, head $\geq 3$ ) and patients without TBI (AIS score, head $<3$ ), as well as according to the transfusion ratio they had received: high FFP:pRBC ratio (FFP:pRBC ratio >1:2) and low FFP:PRBC ratio (FFP:PRBC ratio $\leq 1: 2$ ). In addition, morbidity and mortality between the two groups were compared.

Results: A total of 1,250 data sets of severely injured patients from the TR-DGU between 2002 and 2008 were analyzed. The mean patient age was 42 years, the majority of patients were male (72.3\%), the mean ISS was 41.7 points ( \pm 15.4 SD) and the principal mechanism of injury was blunt force trauma (90\%). Mortality was statistically lower in the high FFP:pRBC ratio groups versus the low FFP:pRBC ratio groups, regardless of the presence or absence of TBI and across all time points studied $(P<0.001)$. The frequency of sepsis and multiple organ failure did not differ among groups, except for sepsis in patients with TBI who received a high FFP:pRBC ratio transfusion. Other secondary end points such as ventilator-free days, length of stay in the ICU and overall in-hospital length of stay differed significantly between the two study groups, but not when only data for survivors were analyzed.

Conclusions: These results add more detailed knowledge to the concept of a high FFP:pRBC ratio during early aggressive resuscitation, including massive transfusion, to decrease mortality in severely injured patients both with and without accompanying TBI. Future research should be conducted with a larger number of patients to prove these results in a prospective study.

\footnotetext{
* Correspondence: Marc.Maegele@t-online.de

'Department of Trauma and Orthopedic Surgery, University of Witten/ Herdecke, Cologne-Merheim Medical Centre (CMMC), Ostmerheimerstrasse 200, D-51109 Cologne, Germany

Full list of author information is available at the end of the article
}

\section{Biomed Central}




\section{Introduction}

Hemorrhage is one of the main causes of death after trauma. Approximately $40 \%$ of severely injured patients die as a result of acute exsanguination [1]. Uncontrolled hemorrhage after trauma is often associated with acidosis, hypothermia and coagulopathy, forming the so-called "lethal triad" [2]. Recently, acute traumatic coagulopathy (ATC) has been identified as a key factor to trigger ongoing hemorrhage after trauma [3]. Ongoing hemorrhage, when combined with ATC, is frequently not controlled by current resuscitation protocols using crystalloids and transfusion of packed red blood cell (pRBC) concentrates [2]. As a consequence, several authors have advocated the early use of fresh frozen plasma (FFP) to control ATC in the early phase after trauma. Despite persistent conflicting data on this issue due to suboptimal methodologies, different retrospective studies have demonstrated a survival benefit of transfusion strategies using an early and more balanced ratio between FFP and pRBC transfusions in patients with ATC requiring massive transfusion within the first 24 hours after hospital admission $(\geq 10 \mathrm{U}$ of pRBCs) [2,4-11]. These analyses, however, have not attempted to determine whether patients with severe traumatic brain injury (TBI) had the same association of improved survival with increased FFP:pRBC ratios. Headinjured patients are particularly prone to developing acute coagulation disorders, and the frequency of these disorders upon emergency room (ER) arrival in patients with blunt TBI has been reported to be as high as $22.7 \%$ [12]. In patients with TBI, there is a component of local tissue release of thromboplastin and low platelets. The aim of the present study was to analyze whether a transfusion regimen using a high FFP:pRBC ratio (FFP:pRBC ratio $>1: 2$ ) would be associated with a similar survival benefit in severely injured patients with TBI (AIS score, head $\geq 3$ ) as previously demonstrated for patients without TBI requiring massive transfusion ( $\geq 10 \mathrm{U}$ of $\mathrm{pRBCs}$ ).

\section{Materials and methods}

We conducted a retrospective analysis of data from severely injured patients documented in the TraumaRegistry of the Deutsche Gesellschaft für Unfallchirurgie (TR-DGU).

\section{The TraumaRegistry of the Deutsche Gesellschaft für Unfallchirurgie}

The TR-DGU was founded in 1993 by the German Society of Trauma Surgery (Deutsche Gesellschaft für Unfallchirurgie (DGU)). It is a prospective, multicenter, standardized and anonymous documentation of multiply injured trauma patients at four consecutive posttrauma phases from injury to hospital discharge: (1) prehospital phase, (2) emergency room and initial surgery (until admission to the intensive care unit (ICU)), (3) ICU and (4) outcome status at discharge and description of injuries and procedures. The registry contains detailed information on patient demographics; injury patterns; comorbidities; pre- and in-hospital management; time course; relevant laboratory findings, including data on transfusions; and the outcome of each patient. All injuries are coded using the Abbreviated Injury Scale (AIS). Through 2008 data from a total of 42,248 trauma patients had been entered into the registry, with approximately 6,000 new cases added each year. Since the introduction of the online version of the registry in 2002, the use of FFP has routinely been documented. Between 2002 and 2008, 31,124 patients were entered into the registry. There are 166 hospitals affiliated with the registry, mostly in Germany $(n=107)$, of which 116 actually contribute data to the database. Contributing hospitals are mostly level I trauma centers. The data are not dominated by single trauma centers, but this does not exclude potential center effects due to different levels and strategies of trauma care. The TR-DGU is a voluntary registry, and participation is free of charge. The trauma registry is approved by the review board of the German Society of Trauma Surgery (DGU) and is in compliance with the institutional requirements. As the TR-DGU is an anonymous registry, the Institutional Review Board waived the need for informed consent.

\section{Data analysis}

Inclusion criteria for the present analysis were primary admission, patient age $\geq 16$ years, severe injury (ISS $\geq 16$ ) and massive transfusion ( $\geq 10 \mathrm{U}$ of $\mathrm{pRBCs})$ from the ER until ICU admission. Patients who died within the first hour after admission were excluded. Patients were subdivided into patients with TBI (AIS score, head $\geq 3$ ) and patients without TBI (AIS score, head $<3$ ) and according to the ratio of plasma to blood that they received during the initial massive transfusion: high (FFP:pRBC ratio $>1: 2$ ) or low (FFP:pRBC ratio $\leq 1: 2$ ). The FFP:pRBC ratio distribution is shown in Figure 1. All transfused FFP was fresh and frozen (that is, no thawed plasma). Only pRBCs and FFP that had been transfused between ER and ICU admissions were considered. The mean time $( \pm$ standard deviation (SD)) from ER arrival to ICU admission, including emergency operative procedure time, was $331 \pm 144$ minutes. The mean time $( \pm \mathrm{SD})$ required for initial diagnostic procedures and treatment in the ER was $65 \pm 42$ minutes.

The primary outcome was mortality ( 6 hours, 24 hours 30 days as well as overall in-hospital mortality). Secondary outcomes included sepsis (defined by Bone et al. [13] as adequate symptoms in combination with evidence of germs), multiorgan failure (defined by Sepsis-Related Organ Failure Assessment score $\geq 3$ ), ventilator-free days 


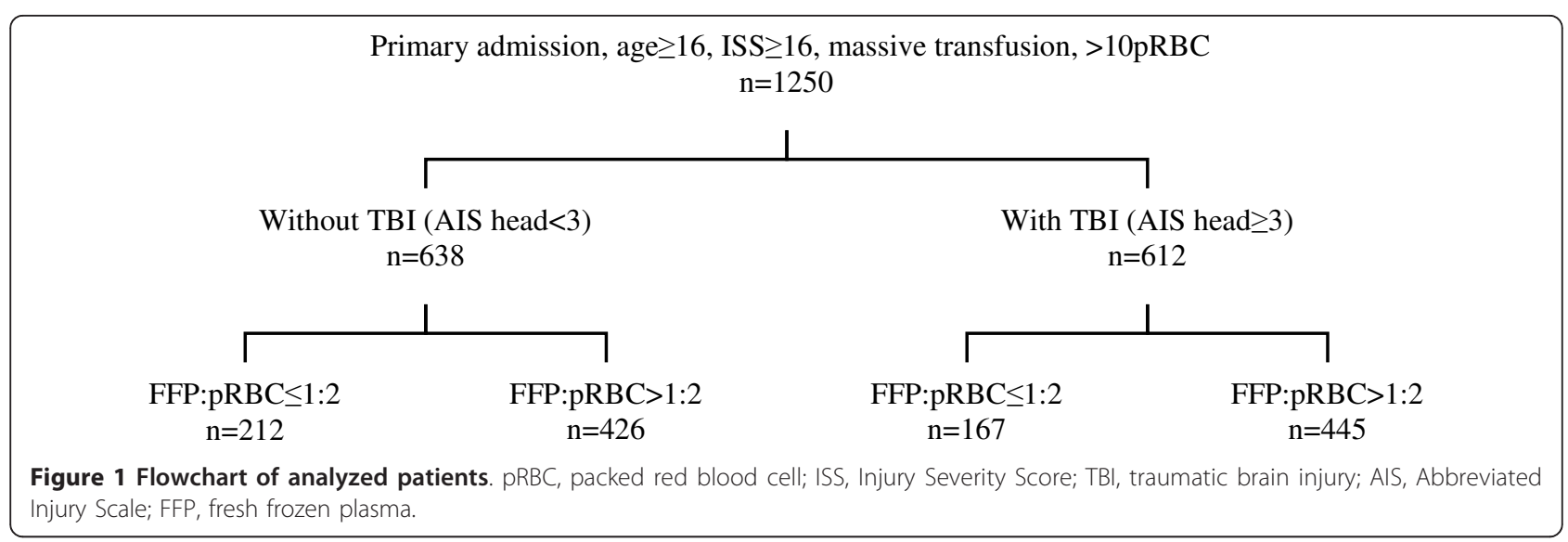

(calculated for a total of 30 days), ICU length of stay and hospital length of stay (HLOS).

\section{Statistical analysis}

Demographic and clinical data are presented as means \pm $\mathrm{SD}$ for continuous variables and as percentages for categorical variables. For continuous variables, normal distributions were analyzed by using the Shapiro-Wilk test. To detect differences between the patient groups, Student's $t$-test or the Mann-Whitney $U$ test was performed, depending on the underlying distribution. For categorical variables, a $\chi^{2}$ test was used. Thirty-day survival rates are presented using Kaplan-Meier curves, and differences among the subgroups with and without TBI were tested using the log-rank test.

Multivariate logistic regression analysis was performed with hospital mortality as the dependent variable. Results are presented as odds ratios (ORs) with 95\% confidence intervals (95\% CIs). The following variables were considered as independent predictors: (1) transfusion ratio (FFP:pRBC ratio $\leq 1: 2$ and FFP:pRBC ratio $>1: 2$ ), (2) Revised Injury Severity Classification (RISC) score as a summary measure for known risk factors for mortality and (3) emergency operations. The RISC score was developed on the basis of data from the TR-DGU to calculate the probability of death for individual patients on the basis of the following 11 variables: age, new ISS, head injury, severe injuries of the extremities, Glasgow Coma Scale score, partial thromboplastin time, base excess, cardiac arrest and indirect signs of bleeding (systolic blood pressure $<90 \mathrm{mmHg}$, hemoglobin $<9 \mathrm{~g} / \mathrm{dl}$ and massive transfusion during initial resuscitation) [14]. A comparison with other established scores (for example, Revised Trauma Score and Trauma Injury Severity Score) demonstrated the superior precision, discrimination and calibration of the RISC score. Statistics were calculated using the SPSS version 18 software package (SPSS, Inc., Chicago, IL, USA).

\section{Results}

A total of 1,250 data sets of severely injured patients derived from the TR-DGU between 2002 and 2008 were eligible for analysis. The mean patient age $( \pm S D)$ was $41.8 \pm 16.3$ years, the vast majority of patients were male $(72.3 \%)$, the mean injury severity $( \pm S D)$ reflected by ISS was $41.7 \pm 15.4$ points and the mechanism of injury was predominantly blunt force trauma (90\%). Patients were divided into four subgroups as described above and as shown in Figure 1. Table 1 summarizes the demographic and physiological characteristics of patients within their respective subgroups. As expected, patients with TBI had sustained a higher overall magnitude of injury as compared to patients without TBI $(P<$ 0.001). Patients without relevant TBI and a high FFP: pRBC ratio were slightly younger and more frequently male than patients who received a low FFP:pRBC ratio transfusion. Physiological variables such as heart rate and blood pressure both at the trauma scene and upon ER arrival were comparable between all groups. Patients in the low FFP:pRBC ratio groups were slightly more shocked than patients with a high FFP:pRBC ratio upon ER admission as reflected by lower base excess. The volume loading during the prehospital and early inhospital phases of care did not differ among the groups, except for the amount of crystalloids in the ER in patients with TBI (Table 2). Among all subgroups, the vast majority $(>80 \%)$ of patients presented with manifest clinical and laboratory signs of coagulopathy upon ER arrival (Table 1). The number of transfused pRBC units was comparable across all subgroups, while the amount of plasma transfused differed considerably between the groups according to the definition given in Table 2 .

In general, the mortality rate was lower in the high FFP: pRBC ratio groups as compared to the low FFP:pRBC ratio groups, regardless of the presence or absence of TBI and across all time points (Table 3 and Figures 2 and 3). Figure 4 shows Kaplan-Meier 30-day survival curves for 
Table 1 Basic characteristics and physiological data of patients according to their study groups ${ }^{\mathrm{a}}$

\begin{tabular}{|c|c|c|c|c|c|c|}
\hline \multirow[b]{2}{*}{ Patient characteristics } & \multicolumn{3}{|c|}{ AIS score, head $<3$} & \multicolumn{3}{|c|}{ AIS score, head $\geq 3$} \\
\hline & FFP:pRBC ratio $\leq 1: 2$ & FFP:pRBC ratio $>1: 2$ & $P$ value & FFP:pRBC ratio $\leq 1: 2$ & FFP:pRBC ratio $>1: 2$ & $P$ value \\
\hline Number of patients (\%) & $212(17 \%)$ & $426(34.1 \%)$ & & $167(13.4 \%)$ & $445(35.6 \%)$ & \\
\hline Mean age, yr $( \pm S D)$ & $45.9 \pm 20$ & $42.0 \pm 17.2$ & 0.049 & $40.5 \pm 19.2$ & $40.2 \pm 18.2$ & 0.947 \\
\hline Males, n (\%) & $149(70.3 \%)$ & $330(77.5 \%)$ & 0.048 & $111(66.5 \%)$ & $314(70.6 \%)$ & 0.327 \\
\hline Blunt trauma mechanism, $n(\%)$ & $191(90.1 \%)$ & $379(89 \%)$ & 0.722 & $158(94.6 \%)$ & 417 (93.7\%) & 0.676 \\
\hline Mean ISS, points $( \pm S D)$ & $36.7 \pm 15.3$ & $35.4 \pm 13.5$ & 0.532 & $49.5 \pm 14.9$ & $47.2 \pm 14.1$ & 0.143 \\
\hline $\begin{array}{l}\text { Mean GCS at trauma scene, } \\
\text { points }\end{array}$ & 10 & 12 & 0.001 & 7 & 7 & 0.571 \\
\hline $\begin{array}{l}\text { Mean HR at trauma scene, } \\
\text { beats/min }( \pm S D)\end{array}$ & $105 \pm 31$ & $106 \pm 25$ & 0.907 & $106 \pm 33$ & $105 \pm 28$ & 0.240 \\
\hline $\begin{array}{l}\text { Mean } \mathrm{HR} \text { at hospital admission, } \\
\text { beats/min }( \pm \mathrm{SD})\end{array}$ & $105 \pm 27$ & $102 \pm 26$ & 0.222 & $103 \pm 31$ & $104 \pm 26$ & 0.686 \\
\hline $\begin{array}{l}\text { Mean systolic BP at trauma } \\
\text { scene, } \mathrm{mmHg}( \pm \mathrm{SD})\end{array}$ & $91 \pm 34$ & $95 \pm 31$ & 0.245 & $90 \pm 35$ & $93 \pm 35$ & 0.792 \\
\hline $\begin{array}{l}\text { Mean systolic BP at hospital } \\
\text { admission, } \mathrm{mmHg}( \pm \mathrm{SD})\end{array}$ & $93 \pm 36$ & $95 \pm 30$ & 0.411 & $92 \pm 34$ & $96 \pm 30$ & 0.313 \\
\hline Mean Hb, g/dl ( \pm SD) & $8.0 \pm 2.7$ & $8.4 \pm 2.8$ & 0.09 & $8.0 \pm 2.9$ & $8.4 \pm 3.0$ & 0.13 \\
\hline Mean BE, mM/l ( \pm SD) & $-8.9 \pm 6.8$ & $-7.0 \pm 5.9$ & 0.08 & $-9.3 \pm 6.5$ & $-7.3 \pm 6.4$ & 0.01 \\
\hline Mean PTT, seconds $( \pm S D)$ & $51.9( \pm 32.8)$ & $50.9( \pm 31.1)$ & 0.63 & $72.3( \pm 49.3)$ & $60.7( \pm 37.5)$ & 0.06 \\
\hline Mean quick, \% $( \pm S D)$ & $54( \pm 23.7)$ & $56( \pm 23.4)$ & 0.33 & $54( \pm 24.2)$ & $53( \pm 23.0)$ & 0.69 \\
\hline Mean platelets, $\mathrm{nl}( \pm \mathrm{SD})$ & $158( \pm 77.7)$ & $165( \pm 75.6)$ & 0.30 & $152( \pm 74.0)$ & $160( \pm 71.6)$ & 0.23 \\
\hline Coagulopathy, n (\%) & $152(87.4 \%)$ & $298(82.3 \%)$ & 0.14 & $118(90.1 \%)$ & $344(88.4 \%)$ & 0.61 \\
\hline
\end{tabular}

${ }^{a}$ AIS, Abbreviated Injury Scale; FFP, fresh frozen plasma; pRBC, packed red blood cell; SD, standard deviation; ISS, Injury Severity Score; GCS, Glasgow Coma Scale; $\mathrm{HR}$, heart rate; $\mathrm{BP}$, blood pressure; $\mathrm{Hb}$, hemoglobin; $\mathrm{BE}$, base excess; $\mathrm{PTT}$, partial thromboplastin time. Coagulopathy was defined by the presence of at least one of the following conditions: PTT $<38$ seconds, Quick $<70 \%$ and platelets $<100,000 / \mu l$. In the TR-DGU the prothrombin time (PT) is documented as Quick's value where a value of $<70 \%$ is equivalent to an INR (International Normalized Ratio) $>1.3$.

all subgroups, with the highest survival rate being in patients without TBI who received a high FFP:pRBC ratio. The lowest survival rates were found in patients with TBI who were transfused with a low FFP:pRBC ratio. The differences in survival between the high and low FFP:pRBC ratio groups were statistically significant within each TBI subgroup $(P<0.001$; log-rank test). The frequency of sepsis and multiple organ failure did not differ among the groups, except for sepsis in patients with TBI who were transfused with a high FFP:pRBC ratio $(>1: 2)$. Other secondary end points, such as ventilatorfree days, ICU length of stay and overall in-hospital length of stay differed significantly between the ratio groups, but not when analyzed for survivors only.

Table 2 Fluids and blood products transfused during initial resuscitation ${ }^{a}$

\begin{tabular}{|c|c|c|c|c|c|c|}
\hline \multirow[b]{2}{*}{$\begin{array}{l}\text { Transfusions and time } \\
\text { intervals }\end{array}$} & \multicolumn{3}{|c|}{ AIS score, head $<3$} & \multicolumn{3}{|c|}{ AIS score, head $\geq 3$} \\
\hline & FFP:pRBC ratio $\leq 1: 2$ & FFP:pRBC ratio $>1: 2$ & $P$ value & FFP:pRBC ratio $\leq 1: 2$ & FFP:pRBC ratio $>1: 2$ & $P$ value \\
\hline \multicolumn{7}{|l|}{ Fluids prehospital } \\
\hline Mean crystalloids, ml ( \pm SD) & $1,491 \pm 937$ & $1,391 \pm 819$ & 0.433 & $1,354 \pm 888$ & $1,297 \pm 743$ & 0.981 \\
\hline Mean colloids, ml ( \pm SD) & $991 \pm 615$ & $939 \pm 579$ & 0.272 & $982 \pm 654$ & $945 \pm 475$ & 0.957 \\
\hline \multicolumn{7}{|l|}{ Fluids emergency room } \\
\hline Mean crystalloids, $\mathrm{ml}( \pm \mathrm{SD})$ & $3,549 \pm 2,858$ & $3,981 \pm 2,959$ & 0.071 & $3,122 \pm 2,640$ & $4,000 \pm 3,036$ & $<0.001$ \\
\hline Mean colloids, ml ( \pm SD) & $1,648 \pm 1,478$ & $1,802 \pm 1,592$ & 0.080 & $1,568 \pm 1,247$ & $1,788 \pm 1,371$ & 0.112 \\
\hline Mean pRBC transfusion, $n( \pm \mathrm{SD})$ & $19.5 \pm 11.2$ & $19.5 \pm 11.9$ & 0.916 & $18.4 \pm 9.8$ & $18.9 \pm 10.7$ & 0.980 \\
\hline $\begin{array}{l}\text { Mean FFP transfusion, } n( \pm S D) \\
(\text { min-max })\end{array}$ & $5.7 \pm 5.2(0$ to 32$)$ & $18.0 \pm 12.3(6$ to 88$)$ & $<0.001$ & $5.5 \pm 4.8(0$ to 30$)$ & $17.8 \pm 10.4(6$ to 84$)$ & $<0.001$ \\
\hline $\begin{array}{l}\text { Mean minutes from trauma } \\
\text { scene to ER }( \pm S D)\end{array}$ & $59( \pm 39)$ & $64( \pm 40)$ & 0.115 & $66( \pm 44)$ & $69( \pm 44)$ & 0.464 \\
\hline $\begin{array}{l}\text { Mean minutes from hospital } \\
\text { admission including ER and } \\
\text { operation theater to ICU } \\
\text { transfer }( \pm S D)\end{array}$ & $303( \pm 144)$ & $350( \pm 140)$ & $<0.001$ & $290( \pm 147)$ & $337( \pm 143)$ & 0.001 \\
\hline
\end{tabular}

${ }^{a}$ AIS, Abbreviated Injury Scale; FFP, fresh frozen plasma; pRBC, packed red blood cell; SD, standard deviation; ER, emergency room; ICU, intensive care unit. 
Table 3 Morbidity and mortality according to study groups ${ }^{\text {a }}$

\begin{tabular}{|c|c|c|c|c|c|c|}
\hline \multirow[b]{2}{*}{ Morbidity and mortality } & \multicolumn{3}{|c|}{ AIS score, head $<3$} & \multicolumn{3}{|c|}{ AIS score, head $\geq 3$} \\
\hline & FFP:pRBC ratio $\leq 1: 2$ & FFP:pRBC ratio $>1: 2$ & $P$ value & FFP:pRBC ratio $\leq 1: 2$ & FFP:pRBC ratio $>1: 2$ & $P$ value \\
\hline Sepsis, $n(\%)$ & $31(21.5 \%)$ & $91(23.6 \%)$ & 0.608 & $19(15.7 \%)$ & $98(24.9 \%)$ & 0.035 \\
\hline Multiorgan failure, $n(\%)$ & $86(58.5 \%)$ & $211(55.7 \%)$ & 0.557 & $80(67.2 \%)$ & $276(71.3 \%)$ & 0.393 \\
\hline Mean ventilator-free days $( \pm$ SD) & $8.7 \pm 11.2$ & $12.8 \pm 11.6$ & $<0.001$ & $4.3 \pm 8.1$ & $6.1 \pm 9.0$ & 0.006 \\
\hline $\begin{array}{l}\text { Survivors' mean ventilation-free } \\
\text { days }( \pm S D)\end{array}$ & $16.9 \pm 10.2$ & $17.4 \pm 10.1$ & 0.647 & $11.5 \pm 9.6$ & $11.1 \pm 9.7$ & 0.825 \\
\hline Mean ICU LOS, days $( \pm S D)$ & $14.7 \pm 19.4$ & $18.5 \pm 20.1$ & $<0.001$ & $12.5 \pm 18.5$ & $18.2 \pm 21.3$ & $<0.001$ \\
\hline Survivors' mean ICU LOS, days ( \pm SD) & $24.7 \pm 20.5$ & $23.1 \pm 20.6$ & 0.335 & $29.0 \pm 20.8$ & $29.7 \pm 22.3$ & 0.703 \\
\hline Mean HLOS, days ( \pm SD) & $30.2 \pm 40.3$ & $43.3 \pm 40.2$ & $<0.001$ & $20.6 \pm 30.1$ & $29.9 \pm 36.4$ & $<0.001$ \\
\hline Survivors' mean HLOS, days $( \pm \mathrm{SD})$ & $54.3 \pm 43.0$ & $56.3 \pm 38.5$ & 0.361 & $49.2 \pm 32.3$ & $49.9 \pm 36.8$ & 0.934 \\
\hline 6-hour mortality, n (\%) & $74(34.9 \%)$ & $45(10.6 \%)$ & $<0.001$ & $55(32.9 \%)$ & $69(15.5 \%)$ & $<0.001$ \\
\hline 24-hour mortality, n (\%) & $85(40.1 \%)$ & $47(17.4 \%)$ & $<0.001$ & $74(44.3 \%)$ & $110(24.7 \%)$ & $<0.001$ \\
\hline 30-day mortality, $n$ (\%) & $97(45.8 \%)$ & $105(24.6 \%)$ & $<0.001$ & $104(62.3 \%)$ & $199(44.7 \%)$ & $<0.001$ \\
\hline In-hospital overall mortality, $n$ (\%) & $102(48.1 \%)$ & $114(26.8 \%)$ & $<0.001$ & $104(62.3 \%)$ & $203(45.6 \%)$ & $<0.001$ \\
\hline
\end{tabular}

aAIS, Abbreviated Injury Scale; FFP, fresh frozen plasma; PRBC, packed red blood cell; ICU, intensive care unit; LOS, length of stay; SD, standard deviation; HLOS, hospital length of stay.

Multivariate logistic regression analysis was performed according to the presence or absence of TBI with hospital mortality as the dependent variable. The analysis identified a high FFP:pRBC transfusion ratio $(>1: 2)$ as an independent predictor for survival in both subgroups (Table 4). Interestingly, severely injured patients who had sustained a TBI obviously benefited more from the high FFP:pRBC ratio strategy as compared to patients without TBI (ORs, 0.48 vs. 0.70). In both groups, the RISC score was independently associated with mortality. Multivariate analysis was also used to calculate all RISC score variables entered into the model, instead of the cumulative score, which yielded the same results. The additional consideration of emergency craniotomy in the TBI group did not improve the model (OR, $1.1 ; P=0.6$ ).

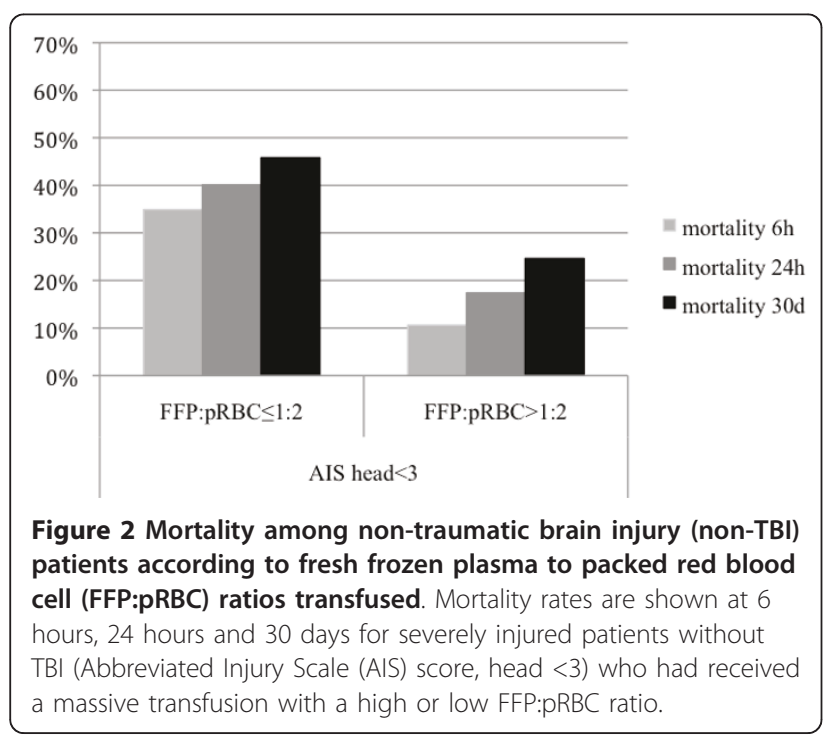

\section{Discussion}

Although there is still debate about the early and aggressive use of FFP in a more balanced 1:1 ratio to pRBCs to correct ATC, the majority of studies published to date have emphasized its use and have associated this approach with improved survival rates among severe trauma patients requiring massive transfusions $[4,6-11,15,16]$. These studies, however, have not attempted to determine whether TBI patients have the same association of improved survival with a more balanced transfusion of FFP and pRBCs. In patients with TBI, there is a component of local tissue release of thromboplastin and low platelets. In the present study, we retrospectively investigated whether a high FFP:pRBC transfusion ratio (FFP:pRBC ratio $>1: 2)$ during massive transfusion ( $\geq 10 \mathrm{U}$ of pRBCs) in the acute phase after trauma would be associated with a

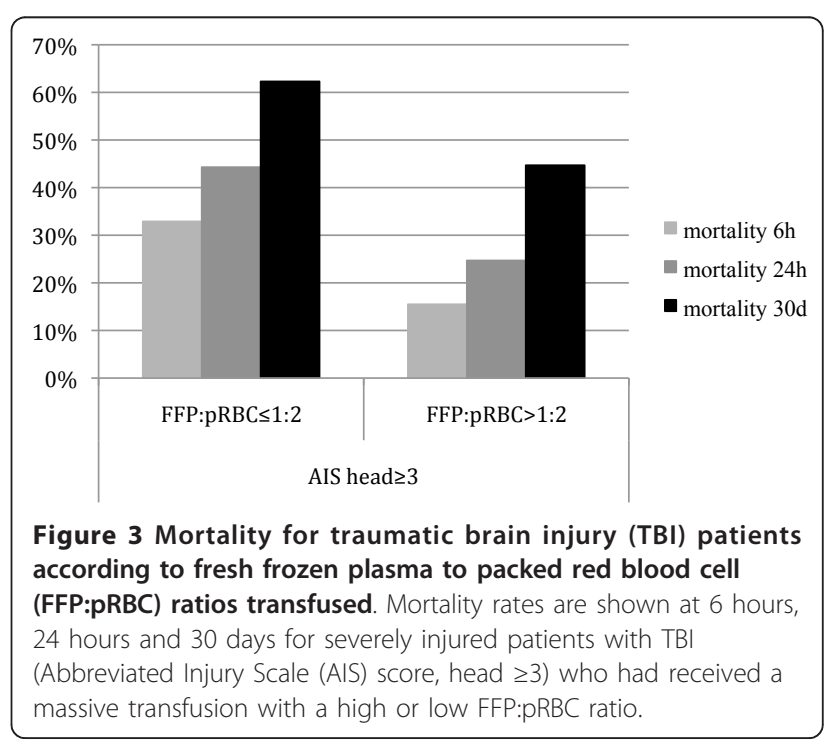




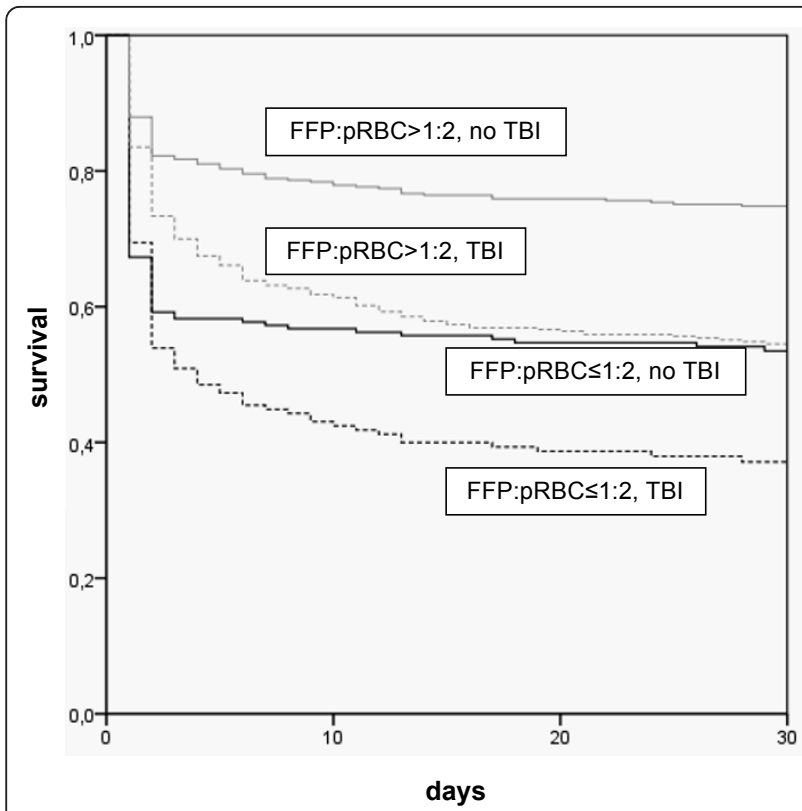

Figure 4 The 30-day survival rates for patients with different transfusion regimes subdivided into patients with and without traumatic brain injury (TBI). Kaplan-Meier analysis was performed to assess the outcomes of severely injured patients who had received a high FFP:pRBC ratio transfusion (FFP:PRBC $>1: 2$ ) versus those who had received a low FFP:pRBC ratio transfusion (FFP:EK $\leq 1: 2$ ), subdivided into patients with TBI (Abbreviated Injury Scale (AIS) score, head $\geq 3$ ) and patients without TBI (AIS score, head <3).

similar survival benefit in patients with TBI as was previously observed for patients without TBI.

As we describe in the Results, the rates for acute and late mortality were both lower in high FFP:pRBC ratio groups compared to low FFP:pRBC ratio groups, regardless of the presence or absence of TBI. Despite the fact that mortality rates in patients with TBI were generally higher compared to patients without TBI, obviously due to the higher magnitude of overall injury sustained, this result indicates that the concept of a high transfusion ratio approach in the acute trauma setting requiring massive transfusion may also be beneficial for patients with accompanying TBI. This assumption is further supported by the results from our logistic regression analysis, which identified a high FFP:pRBC ratio to be an independent predictor for survival, especially in TBI patients. As the high FFP:pRBC ratio effect on survival has been observed as an early effect, immediate introduction of this approach after ER admission may be of crucial importance as soon as clinical and laboratory signs indicate an individual at risk for massive transfusion. To support the clinician, several scoring systems to enable early identification of patients at risk for massive transfusion and to predict the probability for massive transfusion at a very early stage have been developed and validated, such as the Assessment of Blood Consumption score or the predictive model for massive transfusion described by Cotton et al. [17] and McLaughlin et al. [18]. Recently, our group [19,20] has introduced the Trauma Associated Severe Hemorrhage score as a useful instrument to calculate the probability of massive transfusion as a surrogate for life-threatening hemorrhage after severe trauma.

Patients with TBI are at increased risk for developing coagulation abnormalities in the acute phase after trauma, and the clinical frequency of these disorders in blunt TBI patients has been estimated to be as high as $22.7 \%$ [12]. The coagulopathy after TBI is thought to be the result of injury-mediated local release of thromboplastin into the systemic circulation, although the precise mechanisms that cause systemic coagulopathy after TBI are as yet unknown [12,21,22]. In 1979, Mauersberger [23] concluded on the basis of his clinical investigations that the release of tissue thromboplastin after severe brain injury can lead to a consumption coagulopathy. Hulka et al. [24] reported a similar coagulopathy after blunt TBI that was associated with a high frequency of death. These observations regarding the early

Table 4 Logistic regression analysis ${ }^{a}$

\begin{tabular}{|c|c|c|c|c|}
\hline Non-TBI versus TBI patients & Regression coefficient $\beta$ & Standard error of the mean & $P$ value & Odds ratio $(95 \% \mathrm{Cl})$ \\
\hline \multicolumn{5}{|l|}{ No TBI } \\
\hline FFP:pRBC ratio $>1: 2$ & -0.36 & 0.28 & 0.200 & 0.70 (0.04 to 1.21$)$ \\
\hline RISC score & 0.75 & 0.09 & $<0.001$ & 2.13 (1.77 to 2.56$)$ \\
\hline Emergency operation & 0.09 & 0.30 & 0.759 & 1.10 (0.61 to 1.98$)$ \\
\hline Constant & 0.02 & 0.26 & 0.947 & 1.02 \\
\hline \multicolumn{5}{|l|}{$\mathrm{TBI}$} \\
\hline FFP:pRBC ratio $>1: 2$ & -0.73 & 0.27 & 0.006 & 0.48 (0.29 to 0.81$)$ \\
\hline RISC score & 0.56 & 0.07 & $<0.001$ & 1.75 (1.52 to 2.02$)$ \\
\hline Emergency operation & 0.45 & 0.29 & 0.112 & 1.57 (0.90 to 2.75$)$ \\
\hline Constant & 0.14 & 0.24 & 0.543 & 1.16 \\
\hline
\end{tabular}

${ }^{\mathrm{a}} \mathrm{TBI}$, traumatic brain injury; $95 \% \mathrm{Cl}, 95 \%$ confidence interval; FFP, fresh frozen plasma; pRBC, packed red blood cell; RISC, Revised Injury Severity Classification. Logistic regression analysis was performed with mortality as a dependent variable and FFP:pRBC ratio, RISC score and emergency operations as independent variables according to the presence or absence of TBI. 
substitution of plasma have been advocated. More recently, Cohen et al. [25] emphasized the role of hypoperfusion and the protein $\mathrm{C}$ pathway for the development of coagulopathy after TBI. These authors concluded that TBI alone does not initiate coagulopathy, but must be coupled with hypoperfusion to lead to coagulation derangement associated with the activation of the protein $C$ pathway.

One criticism associated with transfusion of high volumes of FFP during early acute resuscitation after trauma has been related to its potential harmful effects [26]. Potential risks of FFP transfusion include transfusion-related acute lung injury (TRALI) [27], transfusionassociated circulatory overload [28], allergic reaction and transmission of infectious diseases such as human immunodeficiency virus, hepatitis $B$ and $C$ viruses and prion diseases [26]. To date, TRALI is the most important cause of transfusion-associated morbidity and mortality [29]. In previous retrospective studies, a trend was observed in that the survival benefit associated with the high FFP:pRBC ratio approach was bought on the account of increasing frequencies of complications, such as nosocomial infections, sepsis and organ failure, resulting in prolonged days on ventilators and increased ICU and overall in-hospital stays $[16,30]$. When considering all patients included in the present study, survivors' and nonsurvivors' duration of ventilation, ICU length of stay and HLOS were significantly longer for patients who had received a high FFP:pRBC transfusion ratio. This observation might be due to prolonged survival among patients with a high FFP:pRBC transfusion ratio. When focusing on survivors only, the duration of ventilation, ICU length of stay and HLOS did not differ statistically between the high and low FFP:pRBC transfusion ratio groups. The incidence of multiple organ failure was higher in patients with more severe injuries, including TBI, than in patients without TBI $(67 \%$ and $71 \%$ versus $59 \%$ and $56 \%$ according to the transfusion ratios, respectively), but did not differ when the transfusion regimens within the two subgroups were compared. Patients with TBI who received a high FFP:pRBC transfusion ratio developed septic coagulation more often than patients of the same group but with a low FFP:pRBC transfusion ratio.

The present observations are limited by the number of included patients and the study's retrospective design. It should also be mentioned that the observed positive effect of the high FFP:pRBC transfusion ratio could be explained at least in part by a selection bias. This means that patients in whom it was possible to administer large amounts of plasma in parallel to pRBC transfusion did not show a dramatic massive blood loss, which would require quick transfusion of large amounts of blood. Administration of FFP usually requires some time for preparation. To minimize this survivorship bias, we excluded a priori patients who died within the first hour after admission and limited the duration of transfusion to initial resuscitation; that is, only blood products were considered that had been transfused between the time of ER arrival and ICU admission. Snyder et al. [31] additionally included the FFP:pRBC transfusion ratio as a time-dependent covariate in their multivariate analysis. However, since the exact timing of transfusion is not documented in the TR-DGU, and only the cumulative amount of transfused blood products between the time of ER arrival and ICU admission is recorded, we were not able to adjust for survivorship bias in our logistic regression model as was done by Snyder et al. [31]. Furthermore, this study is based on registry data only and is thus limited by the lack of a more detailed description of the coagulation management that was performed, for example, platelet transfusion or the administration of other specific coagulation factors. In this context, Perkins et al. [32,33] and Holcomb et al. [4] previously described the association between the amount of transfused platelets and improved survival. Future research should be conducted with larger patient numbers and using a prospective approach to prove these results.

\section{Conclusions}

Despite the ongoing debate with regard to the early, aggressive use of FFP in a more balanced 1:1 ratio to pRBCs in the acute trauma setting to correct coagulation disorders, the present study provides some more detailed information in favor of this approach. The mortality rates were consistently lower in the high FFP: $\mathrm{pRBC}$ transfusion ratio groups versus the low FFP:pRBC transfusion ratio groups, regardless of the presence or absence of TBI and at all time points studied, indicating that the concept of a high FFP:pRBC transfusion ratio may also be valid for patients with TBI. Regarding survivors, morbidity was comparable for patients with a low or high FFP:pRBC transfusion ratio, regardless of the presence or absence of TBI.

\section{Key messages}

- Retrospective studies have demonstrated a potential survival benefit from transfusion strategies using an early and more balanced ratio between FFP and pRBC transfusions in patients with ATC requiring massive transfusion but results have mostly been derived from non-head injured patients.

- A total of 1,250 data sets of severely injured patients from the TR-DGU from 2002 to 2008 were analyzed to determine whether a transfusion regime using a high FFP:pRBC ratio (FFP:pRBC >1:2) would be associated with a similar survival benefit in 
severely injured patients with TBI (AIS score, head $\geq 3$ ) as demonstrated for patients without TBI requiring massive transfusion ( $\geq 10 \mathrm{U}$ of pRBCs).

- The mortality rates were consistently lower in the high-ratio groups versus the low-ratio groups, regardless of the presence or absence of TBI and at all time points studied $(P<0.001)$.

- The concept of a high FFP:pRBC ratio may also be valid for patients with TBI. Multivariate logistic regression analysis identified a high FFP:pRBC ratio as an independent predictor of survival, especially in TBI patients.

- Future research should be conducted with a larger number of patients to prove these results in a prospective study.

\section{Abbreviations}

AIS: Abbreviated Injury Scale; ATC: acute traumatic coagulopathy; Cl: confidence interval; ER: emergency room; FFP: fresh frozen plasma; HLOS: inhospital length of stay; ICU: intensive care unit; ISS: Injury Severity Scale; LOS: length of stay; OR: odds ratio; pRBC: packed red blood cell; TACO: transfusion-associated circulatory overload; TBI: traumatic brain injury; TRALI: transfusion-related acute lung injury; TR-DGU: TraumaRegistry of the Deutsche Gesellschaft für Unfallchirurgie.

\section{Author details}

'Department of Trauma and Orthopedic Surgery, University of Witten/ Herdecke, Cologne-Merheim Medical Centre (CMMC), Ostmerheimerstrasse 200, D-51109 Cologne, Germany. ${ }^{2}$ Institute for Research in Operative Medicine (IFOM), University of Witten/Herdecke, Cologne-Merheim Medical Center (CMMC), Ostmerheimerstrasse 200, D-51109 Cologne, Germany. ${ }^{3}$ San Antonio Military Medical Center, 3851 Roger Brooke Drive, San Antonio, TX 78234, USA. ${ }^{4}$ Department of Pediatrics, Surgical Critical Care, Department of Surgery, Connecticut Children's Medical Centre (CCMC), 282 Washington Street, Hartford, CT 06106-3322, USA.

\section{Authors' contributions}

SP and MM conceived the study. UN and RL undertook the statistical analysis together with MB and AW. All other authors (SW, MB and PS) contributed to the study design and to data sharing. SP and MM were responsible for writing the manuscript. All authors read and approved the final manuscript.

\section{Competing interests}

The authors declare that they have no competing interests.

Received: 30 June 2010 Revised: 13 October 2010

Accepted: 22 February 2011 Published: 22 February 2011

\section{References}

1. Sauaia A, Moore FA, Moore EE, Moser KS, Brennan R, Read RA, Pons PT: Epidemiology of trauma deaths: a reassessment. J Trauma 1995, 38:185-193.

2. Gonzalez EA, Moore FA, Holcomb JB, Miller CC, Kozar RA, Todd SR, Cocanour CS, Balldin BC, McKinley BA: Fresh frozen plasma should be given earlier to patients requiring massive transfusion. J Trauma 2007, 62:112-119.

3. Brohi $\mathrm{K}$, Singh J, Heron M, Coats T: Acute traumatic coagulopathy. J Trauma 2003, 54:1127-1130

4. Holcomb JB, Wade CE, Michalek JE, Chisholm GB, Zarzabal LA Schreiber MA, Gonzalez EA, Pomper GJ, Perkins JG, Spinella PC, Williams KL, Park MS: Increased plasma and platelet to red blood cell ratios improves outcome in 466 massively transfused civilian trauma patients. Ann Surg 2008, 248:447-458.

5. Holcomb JB, Spinella PC: Optimal use of blood in trauma patients. Biologicals 2010, 38:72-77.
6. Borgman MA, Spinella PC, Perkins JG, Grathwohl KW, Repine T, Beekley AC, Sebesta J, Jenkins D, Wade CE, Holcomb JB: The ratio of blood products transfused affects mortality in patients receiving massive transfusions at a combat support hospital. J Trauma 2007, 63:805-813.

7. Duchesne JC, Hunt JP, Wahl G, Marr AB, Wang YZ, Weintraub SE, Wright MJ, MCSwain NE Jr: Review of current blood transfusions strategies in a mature level I trauma center: were we wrong for the last 60 years? J Trauma 2008, 65:272-278.

8. Maegele M, Lefering R, Paffrath T, Tjardes T, Simanski C, Bouillon B: Redblood-cell to plasma ratios transfused during massive transfusion are associated with mortality in severe multiple injury: a retrospective analysis from the Trauma Registry of the Deutsche Gesellschaft für Unfallchirurgie. Vox Sang 2008, 95:112-119.

9. Scalea TM, Bochicchio KM, Lumpkins K, Hess JR, Dutton R, Pyle A, Bochicchio GV: Early aggressive use of fresh frozen plasma does not improve outcome in critically injured trauma patients. Ann Surg 2008, 248:578-584.

10. Zehtabchi S, Nishiijma DK: Impact of transfusion of fresh-frozen plasma and packed red blood cells in a 1:1 ratio on survival of emergency department patients with severe trauma. Acad Emerg Med 2009, 16:371-378.

11. Spinella PC, Holcomb JB: Resuscitation and transfusion principles for traumatic hemorrhagic shock. Blood Rev 2009, 23:231-240.

12. Wafaisade $A$, Lefering $R$, Tjardes $T$, Wutzler $S$, Simanski $C$, Paffrath $T$, Fischer $\mathrm{P}$, Bouillon B, Maegele M: Acute coagulopathy in isolated blunt traumatic brain injury. Neurocrit Care 2010, 12:211-219.

13. Bone RC: Let's agree on terminology: definitions of sepsis. Crit Care Med 1991, 19:973-976.

14. Lefering R: Development and validation of the revised injury severity classification score for severely injured patients. Eur I Trauma Emerg Surg 2009, 35:437-447.

15. Gunter OL Jr, Au BK, Isbell JM, Mowery NT, Young PP, Cotton BA: Optimizing outcomes in damage control resuscitation: identifying blood product ratios associated with improved survival. J Trauma 2008, 65:527-534.

16. Borgman MA, Spinella PC, Holcomb JB, Blackbourne LH, Wade CE, Lefering $R$, Bouillon B, Maegele M: The effect of FFP:RBC ratio on morbidity and mortality in trauma patients based of massive transfusion prediction score. Vox Sang in press.

17. Cotton BA, Dossett LA, Haut ER, Shafi S, Nunez TC, Au BK, Zaydfudim V, Johnston M, Arbogast P, Young PP: Multicenter validation of a simplified score to predict massive transfusion in trauma. J Trauma 2010, 69(Suppl 1):S33-S39.

18. McLaughlin DF, Niles SE, Salinas J, Perkins JG, Cox ED, Wade CE, Holcomb JB: A predictive model for massive transfusion in combat casualty patients. J Trauma 2008, 64:S57-S63.

19. Yücel N, Lefering R, Maegele M, Vorweg M, Tjardes T, Ruchholtz S, Neugebauer EA, Wappler F, Bouillon B, Rixen D, Polytrauma Study Group of the German Trauma Society: Trauma Associated Severe Hemorrhage (TASH)Score: probability of mass transfusion as surrogate for life threatening hemorrhage after multiple trauma. J Trauma 2006, 60:1228-1237.

20. Borgman MA, Spinella PC, Holcomb JB, Blackbourne LH, Wade CW, Lefering $R$, Bouillon $B$, Maegele M: The effect of FFP:RBC ratio on morbidity and mortality in trauma patients based on massive transfusion predictive score. Crit Care Med 2009, 37:A264.

21. Pathak A, Dutta S, Marwaha N, Singh D, Varma N, Mathuriya SN: Change in tissue thromboplastin content of brain following trauma. Neurol India 2005, 53:178-182.

22. Björklind A, Arvidson S: Occurrence of an extracellular serineproteinase among Staphylococcus aureus strains. Acta Pathol Microbiol Scand B 1977, 85:277-280.

23. Mauersberger W: [Secondary blood coagulation disturbances after severe head injuries (author's transl)] [in German]. Neurochirurgia (Stuttg) 1979, 22:68-72.

24. Hulka F, Mullins RJ, Frank EH: Blunt brain injury activates the coagulation process. Arch Surg 1996, 131:923-928.

25. Brohi K, Cohen MJ, Ganter MT, Matthay MA, Mackersie RC, Pittet JF: Acute traumatic coagulopathy: initiated by hypoperfusion: modulated through the protein C pathway? Ann Surg 2007, 245:812-818.

26. Nascimento B, Callum J, Rubenfeld G, Neto JB, Lin Y, Rizoli S: Clinical review: fresh frozen plasma in massive bleedings - more questions than answers. Crit Care 2010, 14:202. 
27. Spahn DR, Cerny V, Coats TJ, Duranteau J, Fernández-Mondéjar E, Gordini G, Stahel PF, Hunt BJ, Komadina R, Neugebauer E, Ozier Y, Riddez L, Schultz A, Vincent JL, Rossaint R, Task Force for Advanced Bleeding Care in Trauma: Management of bleeding following major trauma: a European guideline. Crit Care 2007, 11:R17.

28. Popovsky MA: Pulmonary consequences of transfusion: TRALI and TACO. Transfus Apher Sci 2006, 34:243-244.

29. Stainsby $D$, Jones $H$, Asher $D$, Atterbury $C$, Boncinelli A, Brant $L$, Chapman CE, Davison K, Gerrard R, Gray A, Knowles S, Love EM, Milkins C, McClelland DB, Norfolk DR, Soldan K, Taylor C, Revill J, Williamson LM, Cohen H, SHOT Steering Group: Serious hazards of transfusion: a decade of hemovigilance in the UK. Transfus Med Rev 2006, 20:273-282.

30. Maegele M, Lefering R, Yücel N, Tjardes T, Rixen D, Paffrath T, Simanski C, Neugebauer E, Bouillon B: Early coagulopathy in multiple injury: an analysis from the German Trauma Registry on 8724 patients. Injury 2007, 38:298-304.

31. Snyder CW, Weinberg JA, McGwin G Jr, Melton SM, George RL, Reiff DA, Cross JM, Hubbard-Brown J, Rue LW, Kerby JD: The relationship of blood product ratio to mortality: survival benefit or survival bias? I Trauma 2009, 66:358-364.

32. Perkins JG, Cap AP, Weiss BM, Reid TJ, Bolan CD: Massive transfusion and nonsurgical hemostatic agents. Crit Care Med 2008, 36:S325-S339.

33. Perkins JG, Cap AP, Spinella PC, Blackbourne LH, Grathwohl KW, Repine TB, Ketchum L, Waterman P, Lee RE, Beekley AC, Sebesta JA, Shorr AF, Wade CE, Holcomb JB: An evaluation of the impact of apheresis platelets used in the setting of massively transfused trauma patients. J Trauma 2009, 66:S77-S85.

doi: $10.1186 / \mathrm{cc} 10048$

Cite this article as: Peiniger et al:: Balanced massive transfusion ratios in multiple injury patients with traumatic brain injury. Critical Care 2011 15: R68.

\section{Submit your next manuscript to BioMed Central} and take full advantage of:

- Convenient online submission

- Thorough peer review

- No space constraints or color figure charges

- Immediate publication on acceptance

- Inclusion in PubMed, CAS, Scopus and Google Scholar

- Research which is freely available for redistribution

Submit your manuscript at www.biomedcentral.com/submit 